\title{
LA RELACIÓN ENTRE GESTIÓN Y TURISMO, BASADA EN LA EXPERIENCIA DEL VISITANTE
}

\section{THE RELATIONSHIP BETWEEN MANAGEMENT AND TOURISM, BASED ON THE EXPERIENCE OF THE VISITOR}

\author{
Claudia Edith Llontop Diez \\ Universidad de San Martín de Porres, Perú
}

\section{RESUMEN}

Se describe el entorno del turismo y su relación con un mundo conectado, de acuerdo a la teoría de la economía de la experiencia de Pine y Gilmore, la cual propone la necesidad de integrar la gestión como agente impulsor de la experiencia turística desde la comprensión de la experiencia humana; asi como la actitud turística en los diseños o planes de desarrollo de productos turísticos orientando el estudio al desarrollo de un modelo que actúa como vehículo capaz de otorgar al visitante una experiencia turística.

Palabras clave: Economía de la experiencia, experiencia turística, autenticidad y confianza, valor de la experiencia, gestión.

\section{ABSTRACT}

This research describes the tourism environment and its relationship in a connected world according to the economy of the experience theory by Pine and Gilmore. It proposes the need to integrate management as a driving force of the tourism experience from the understanding of the human experience and the tourist attitude in the designs or development plans of tourist products, orienting the study to the development of a model that acts like a vehicle capable of granting the visitor a tourist experience.

Keywords: Economy of experience, tourism experience, authenticity and trust, value of experience, management.

Este es un artículo Open Access bajo la licencia Creative Commons Atribución-NoComercial-Compartirlgual 4.0 


\section{Introducción}

El turismo ha desarrollado un crecimiento y evolución al compás del desarrollo de las sociedades, compás que ha tenido a la tecnología, medios de comunicación y vías de acceso como marcador de este ritmo.

Este fenómeno ha llevado al sector público y privado a evaluar las operaciones turísticas, debido a los diferentes impactos en el medio ambiente, la cultura, la economía y las repercusiones sociales, trayendo como consecuencia la necesidad de mitigar impactos y desarrollar buenas practicas turísticas en el marco de un turismo sostenible.

Por otro lado, esta actividad económica aporta importantes beneficios a países en desarrollo, que se pueden medir en el PBI, en la captación de divisas y en la capacidad de crear nuevas plazas de trabajo, mejorando la calidad de vida y dinamizando la economía a la vez que redistribuye los ingresos en el marco del turismo sostenible.

Integrar al mercado los diversos emprendimientos privados y asociados en el contexto de un destino turístico implica orientarlo a la competitividad y eficiencia, produciendo como resultado la necesidad de crear estrategias de valor orientadas a las necesidades del mercado y enfocadas a la experiencia turística como diferenciador de la oferta.

Las naciones consideran importante el desarrollo de medidas y estrategias como consecuencia de estos beneficios, regulando y desarrollando infraestructura para promover iniciativas y emprendimientos turísticos en todos los niveles.

La experiencia turística, más que una tendencia es parte de la evolución del mercado y las conductas del consumidor, como precisamos líneas arriba, la tecnología ha ido de la mano con el ritmo de crecimiento y desarrollo del turismo, y en ese sentido, se hace más evidente la necesidad de ser más competitivo en el mercado turístico. En un mundo globalizado donde la oferta se diversifica y se orienta a la creación de valor, es imprescindible que los productos turísticos se orienten al diseño de experiencias únicas con capacidad de diferenciar y otorgar un valor atractivo al producto.

La gestión o management impulsa un conjunto de procesos que se hacen tangibles en actividades experienciales para el visitante, no solo asegura la calidad del proceso, también es capaz de establecer las pautas necesarias para una gestión de mejora continua, asegurando la entrega de valor en la experiencia. De esta manera, este conjunto de procesos se debe observar como un todo organizado, como un diseño capaz de otorgar lo necesario para que el visitante logre una experiencia memorable, que involucre sus sentidos, emociones, sentimientos, es decir que favorezca el desarrollo personal de los viajeros. En ese sentido, la investigación busca conceptualizar este conjunto de procesos como un vehículo que otorgue al visitante una experiencia, donde el rol de la gestión actúe como impulsor de este vehículo. 


\section{La economía de la experiencia en el turismo}

En un mundo conectado en donde los productos y servicios se comercializan de manera más competitiva y los usuarios se hacen más exigentes -producto de diferentes contextos como en lo económico, social y tecnológico- encontramos en las tendencias y ofertas turísticas cambios sustanciales que apuntan a generar valor y experiencias en los visitantes.

La nueva economía está basada en valor agregado y experiencias más que en fábricas. Los consumidores demandan mejor calidad y mejores relaciones, y las obtienen. La tecnología abre nuevos mercados y derrumba en cosa de meses a los gigantes que no supieron poner a su cliente como centro (Nouvel, 2017).

Como resultado de estos cambios en el mundo se habla de un nuevo perfil del turista, de segmentos, de un nuevo tipo de cliente, producto del uso de la tecnología móvil, conectividad y otras tecnologías en donde la comunicación e interacción es a través de voz, datos, imágenes y video en tiempo real, que apoyadas en la nube hacen posible comunicarse y entregar información empleándola de diversas formas, socializándola.

Estamos ante el nacimiento de un turista inteligente, muy bien informado, un viajero experimentado que habita en una sociedad «abierta e interconectada» (Arroyo, 2011, p. 21).

Como resultado del uso intensivo de las comunicaciones, flexibilidad en la distribución de los tiempos laborales y la forma de vida conectada, Reyes y Barrado (2005) plantean que el nuevo turista se torna más exigente en torno al valor de su tiempo libre y toma más en serio sus relaciones sociales como su autorrealización en esta nueva concepción de tiempo libre por lo que pone énfasis más, que en la cantidad, en la calidad de las experiencias que se le ofrecen.

El cambio es evidente, las diferentes ofertas nos dan cuenta también de un incremento en los precios si de experiencias únicas se trata, al mismo tiempo que una demanda en crecimiento y una tendencia en el desarrollo de productos turísticos experienciales. Reyes y Barrado (2005, p. 31) indican que la experiencia turística no es un conjunto más de atractivos, se trata de ir a un lugar «para hacer algo». Así pues, ya no basta contar con recursos para ser contemplados, sino que es necesario «construir productos» que permitan realizar actividades, participar.

Pine y Gilmore (1998), detallan de una manera sencilla y practica el desarrollo de esta escalada en su teoría «La economía de la experiencia», citada por muchos autores para referirse a la tendencia del desarrollo de productos turísticos experienciales; considerando a «las experiencias como un producto económico distinto» y producto de la evolución en su llamado modelo de la progresión del valor. 
Figura 1. La progresión del valor económico.

\section{LA PROGRESIÓN DEL VALOR ECONÓMICO}

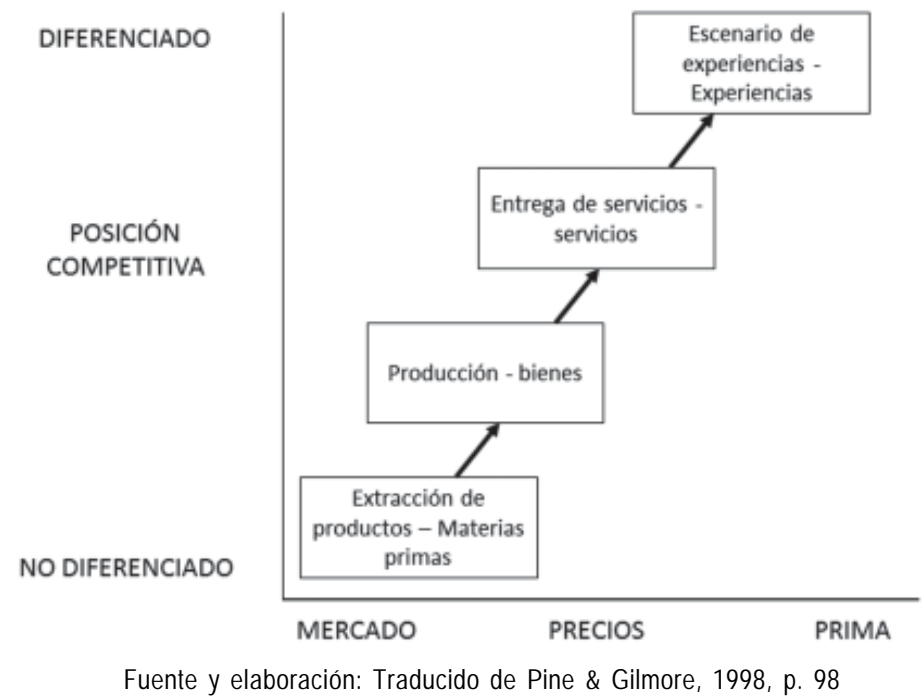

La Figura 1 nos ayuda a comprender como han ido escalando las ofertas económicas por el lado del precio y desde una posición competitiva indefinida hacia la diferenciación. Allí encontramos en un primer momento las materias primas, luego los bienes, los servicios y, finalmente, las experiencias como una oferta económica nueva.

Tabla 1

Distribuciones económicas

\begin{tabular}{lllll}
\hline & & & \\
Oferta Económica & Materias Primas & Bienes & Servicios & Experiencias \\
\hline Economía & Agraria & Industrial & Servicios & Experiencia \\
Función económica & Extraer & Hacer & Entregar & Escenario \\
Naturaleza de la oferta & Fungible & Tangible & Intangible & Memorable \\
Atributo clave & Natural & Estandarizado & Personalizado & Personal \\
Método desuministro & Almacenado a granel & Inventariado después & Entregado bajo & Revelado a lo largo \\
& & de la producción & demanda & de todo el proceso \\
Vendedor & Comerciante & Fabricante & Proveedor & Actor \\
Comprador & Mercado & Usuario & Cliente & Invitado \\
Factores de demanda & Características & Características & Beneficios & Sensaciones \\
& & & &
\end{tabular}

Fuente y elaboración: Traducido de Pine \& Gilmore, 1998, p. 98 
Pine y Gilmore (1998) explican el contexto de la economía de la experiencia como una nueva oferta separada de los servicios cuya función económica es la de crear un escenario para interpretar la experiencia, que traducido a la experiencia turística busca generar las condiciones necesarias para que el visitante logre una experiencia memorable, durante la entrega del servicio y el tiempo de contacto con el cliente en donde los clientes son considerados como invitados y los que interactúan con ellos, considerados como actores.

Para esta nueva oferta económica «una experiencia ocurre cuando una empresa utiliza intencionalmente los servicios como escenario, y los bienes como accesorios, para comprometer a los clientes individuales de una manera que crea un evento memorable» (Pine \& Gilmore, 1998, p. 98).

\section{El visitante y la experiencia turística}

Cuando nos encontramos frente a un plato de nuestra comida favorita en lo que menos pensamos es en factores externos o en racionalizar dialécticamente sobre cómo disfrutar y comer el plato, simplemente nos dedicamos a deleitarnos con nuestros cinco sentidos a disfrutar de la comida.

Las experiencias son intrínsecamente personales, existentes solo en la mente de un individuo quien ha estado involucrado en una emoción (Pine \& Gilmore, 1998, p. 99). Las experiencias como en el turismo son el producto de la percepción, este proceso sucede en el interior de cada persona tal como lo afirma Pine (2009).

La percepción de lo auténtico no solo funciona como variable mediadora entre el self -el yo en psicologíay la experiencia, sino que además influye directamente sobre la satisfacción del turista (George, 2015, p. 149).

La experiencia surge de un contacto natural y espontáneo con la realidad y para ello los sentidos son el nexo que comunica lo que sucede en el exterior con el cerebro. La experiencia también significa la participación de los sentidos y crear recuerdos duraderos (La Liberté, 2005)

\section{Autenticidad e inautenticidad}

En el mercado turístico encontramos atractivos naturales y artificiales como es el caso de Disney, ¿es entonces posible una inauténtica experiencia? La respuesta es no, pues la experiencia ocurre dentro de nosotros, es nuestra reacción a eventos que se nos muestran, explica que la autenticidad, en este sentido, se relaciona al producto y lo que la marca o empresa ofrece al consumidor (Pine, 2009). Cuando la experiencia guarda relación con lo ofrecido, como el confort, la seguridad y otras cualidades, nos referimos a una experiencia auténtica. También cuando los beneficios publicitados u ofrecidos son validados como ciertos por el cliente.

El turista cree estar en presencia de algo auténtico, y por qué lo cree, el paisaje se introduce como real en su percepción. Al trabajar el problema desde la visión del turista, indudablemente, validamos la postura hegemónica del sistema (George, 2015, p. 151). 
Existen diversas posturas y estudios relacionados con la experiencia turística, pero buscamos delimitarla para una mayor comprensión en este estudio, sin embargo, es muy importante mencionar el estudio de Wang (1999), Rethinking authenticity in Tourism experience, pues encontramos que las experiencias turísticas se discuten bajo tres enfoques: objetivismo, constructivismo y posmodernismo, los mismos que discuten sobre si y cómo los objetos recorridos se experimentan como reales.

En turismo, cuando se involucra la naturaleza, el paisaje, la playa, el océano de crucero, las aventuras, la familia, visitar amigos y familiares, etc., lo que el visitante busca es identidad auténtica, sin importar si los «objetos turísticos» son irrelevantes o menos relevantes.

Así los objetos turísticos sean totalmente inauténticos o irrelevantes, es posible buscar una alternativa, porque los turistas lo pueden hacer; es decir, la autenticidad existencial es activada por la experiencia turística (Wang, 1999, p. 365).

Dado que el concepto de autenticidad existencial puede explicar un espectro turístico, el concepto convencional de autenticidad, abre amplias perspectivas para la rejustificación de la autenticidad real, buscando como fundamento las motivaciones turísticas (Wang, 1999, p. 366).

Wang (1999) sugiere además de la autenticidad objetiva y constructiva convencional, una versión existencial, como fuente alternativa justificable para experiencias auténticas en turismo.

Por otro lado, pueden existir muchos o pocos estímulos, naturales o artificiales para percibir la experiencia, en este sentido debemos comprender que también las experiencias tienen un grado, nivel o escala que corresponden a la intensidad de lo que percibimos de ella, y es esa misma intensidad la que promueve que se grabe en nuestra memoria como «experiencia memorable» (Pine, 2009).

\section{Autenticidad y confianza}

La autenticidad en la experiencia turística se relaciona con la confianza, pues a todas luces una experiencia auténtica es el resultado de la correspondencia de lo ofrecido con lo recibido y en ello se implica la promoción, la publicidad y todo ofrecimiento comunicado al visitante en el que se sustentan sus expectativas sobre el producto, poniéndolo a prueba.

Para que la experiencia sea un éxito los gerentes de marketing tendrán que demostrar evidencia de ser dignos de confianza, ofreciendo garantías significativas, siendo confiables, honestos y abiertos en sus negocios y demostrar sus compromisos en todo el proceso de consumo especialmente en cada etapa de la experiencia (Barrios, 2012, p. 80).

\section{El espacio y la actividad como agente de novedad}

Un activador de la experiencia es el sentido de novedad, el mismo que genera atención en el visitante y logra sensibilizarlo, este es el desencadenante de la experiencia, a partir de allí, el visitante afina sus sentidos 
en busca de descubrir más sensaciones. Las experiencias turísticas a menudo se desarrollan en entornos nuevos y unifamiliares, y se podría argumentar que esto predispone a los turistas a «estar atentos» (Moscardo, 2009 p. 105).

Moscardo (2009) precisa que si el lugar donde se desarrolla la experiencia es novedoso, el tipo de actividad no necesariamente puede serlo, en este caso el visitante asume una conducta de «rutina adquirida». Caso contrario a lo que explica el mismo autor, puede darse el caso de un lugar monótono o que no signifique novedad al visitante como por ejemplo una playa común sin atributos excepcionales en el que el factor novedoso es la actividad, por ejemplo, hacer motonáutica. Ambas situaciones no opacan el sentido de novedad que, en este caso, es la actividad o el conjunto de situaciones, ya que desencadenan una atención especial en el visitante por la búsqueda de sensaciones.

Los nuevos escenarios turísticos también pueden ser desafiantes en términos de tener que encontrar la manera de caminar tanto física como mentalmente, por lo que es posible que la atención plena sea provocada por la novedad de la situación (Moscardo, 2009, p. 105).

\section{Entre la realidad y la persona, la actitud surge como un articulador de la experiencia}

El elemento novedad surge como figura motivadora de la actitud, la que se configura como postura frente a la experiencia, la actitud en ese sentido pasa a ser reconocida como una atención a la realidad.

Para Arsenault y Gale (2004):

Un «visitor experience» traducido al español como «experiencia del visitante» sugiere que es algo que se encuentra personalmente, vivido a través de ella, y le afecta. Puede implicar observación o participación. Puede ser activo o pasivo, planeado u oportunista, personal o compartido. (p. 36)

Revela en ese sentido que la experiencia implica una actitud, la misma que puede variar debido a diferentes factores. Implica entonces que la actitud surge como una postura frente a la realidad representada por el nivel atención o conciencia y que puede pasar de un estado pasivo a un activo, de menor o poca atención a uno de mucha atención.

La expectativa del viajero está correlacionada con el conocimiento, emoción, relajación y compras que influyen significativamente en la actitud del viajero. Hay una influencia más fuerte de los factores de motivación hacia la actitud, más que de la expectativa del viajero (Wong, Cheung, \& Wan, 2013, p. 181). En ese sentido, la actitud turística actúa como un motivador de los sentidos y de acuerdo al nivel puede influenciar en un mayor o menor grado la percepción de la experiencia.

Moscardo (2009), refiere la importancia de los «turistas conscientes» en la gestión del turismo, considerándolos valiosos y catalogando esta atención o conciencia en niveles. En el nivel más simple el visitante atento tiene más probabilidades de prestar atención y comprender la solicitud de gestión y seguridad mientras está en el lugar. La atención plena aquí es requisito previo necesario para manejar los comportamientos turísticos. 
En segundo lugar, la atención es una condición necesaria para que el turista aprenda. Para una mayor conciencia y para cambios en actitudes y comportamientos (Moscardo, 2009, p. 104).

La actitud está relacionada con el grado de atención o conciencia del hecho, esta configura el rol del visitante turístico, afecta sus sentidos y lo hace más pasivo o activo dependiendo de cómo los motive. Es así que encontramos visitantes más involucrados con su experiencia, buscando actividades o formas de «hacer».

Este cliente tiene dos formas de vivir la experiencia: activa y pasiva. La primera, cuando se involucra y participa en la actividad: cabalgar, esquiar, nadar o bucear, entre otros. Y la segunda, cuando se entretiene mirando un espectáculo, contempla una puesta de sol o la belleza de un glacial, etc. (Arroyo 2011, p. 22).

Encontramos que la actitud también implica una forma de actuar frente a la experiencia, sea de manera pasiva y/o activa, como respuesta a este nivel de conciencia, en cualquier situación, el visitante desarrolla un papel relevante como protagonista de la experiencia turística.

\section{El significado y la experiencia}

La experiencia implica una reacción del visitante, la misma que potencia y dinamiza la capacidad de atención. Barrios (2012, p. 80), encuentra que las personas reaccionan a la secuencia y duración de los eventos relacionados con el servicio, incluyendo el tiempo como factor determinante para apreciar las experiencias con los sentidos, al mismo tiempo que ésta le otorga algún significado.

Huxley (citado en Fernández-Balaguer, 2008, p. 74) señala: «La experiencia no es lo que te sucede, sino lo que haces con lo que te sucede». La frase nos remite a poder identificar la relación entre la realidad y el hombre, del mismo modo que pone de manifiesto la existencia de una postura o actitud frente al hecho de emitir un juicio respecto de la experiencia.

Por su parte, Stange, Brown, Hilbruner y Hawkins (2011) expresan:

Este evento genera una reacción («ime gustó!» «iLo odié!» «¡Soy muy bueno en la escalada después de todo!»). Y esa reacción se graba en la memoria, en la que el visitante refleja y crea un nuevo significado. En última instancia, la persona, a través de este proceso de creación de significado, aumenta tanto su comprensión del mundo como del yo. (p. 7)

Stange et al. (2011) describen que la experiencia turística se reconoce como un acontecimiento que el visitante experimenta en torno a una actividad o acción por parte de él, en relación a una atracción o recurso, como consecuencia de esta intervención en la realidad obtenemos una reacción o respuesta en un rango de evaluación que varía entre lo negativo y lo positivo, la misma que se graba en la memoria y crea un significado en la persona, este proceso de significado aumenta tanto su comprensión del mundo como del yo, sin duda esta estructura acompañada de otros elementos conforman una experiencia de valor que adquiere significado. 
$\mathrm{Al}$ imaginar experiencias atractivas, usted puede considerar una multiplicidad de dimensiones, estos incluyen un carácter multisensorial, la intensidad y la duración de varios elementos experienciales, la complejidad (o simplicidad), además de otras características de cómo la gente pasa el tiempo. Las consideraciones culturales y las sensibilidades nacionales y locales, así como las experiencias previas de los invitados, influyen en cómo las personas perciben las experiencias.

Nuestra creencia es que no importa cómo se vea, cualquier dimensión de disfrute, por lo general se traduce en la experiencia de ser más memorable, incluso si pocos o ningún detalle pueden ser recordados (Pine \& Gilmore, 2013, p. 35).

En un sentido más amplio las experiencias turísticas provocan situaciones llenas de significado que representan primero parte de un momento de la vida y se conservan en el tiempo como recuerdo memorable.

\section{Articular el valor en la experiencia}

Abordar la experiencia del visitante en turismo es uno de los temas más importantes en la coyuntura actual tanto para la gestión de destinos turísticos como para el diseño de productos. Además, se ha sugerido que la experiencia del cliente es la base esencial de la propuesta de valor entre los proveedores de servicios y los consumidores (Scott, Laws, \& Boksberger, 2013, p. 16).

El objetivo de cualquier negocio es entregar valor para el cliente con un beneficio. En una economía hipercompetitiva, con compradores cada vez mejor informados y con múltiples opciones, una empresa solo puede ganar al ajustar el proceso de entrega de valor y escoger, proveer y comunicar un valor superior (Kotler \& Keller, 2012, p. 33).

En la actualidad, las empresas turísticas buscan por diversos medios desarrollar productos que entreguen valor al cliente. En el ámbito empresarial Michael Porter desarrolla una herramienta para tales fines denominada «cadena de valor». De este modo el valor en la oferta turística al igual que en las empresas se debe asegurar mediante un proceso de gestión que involucre todos los aspectos de la experiencia con el cliente.

En el diseño de productos turísticos encontramos dos aspectos importantes el primero de carácter estructural que se basa en una lógica de trayecto que articula atractivos y servicios en algunos casos; el segundo, orientado a la motivación que sugiere atractivos relacionados a temáticas específicas o una combinación para el disfrute del visitante. El valor en el diseño, se encuentra relacionado con ambas dimensiones siendo articulado por la gestión en un proceso de entrega de valor al cliente.

El mundo competitivo de las empresas turísticas se apoya no solo en la calidad o satisfacción del cliente, pues en un mundo donde se da por hecho un nivel de calidad el gran diferencial lo otorga la experiencia del cliente, pues ella tiene la capacidad de crear valor y vínculos fuertes entre la marca y el consumidor, relación que Voss (2004) considera difícil de romper por los competidores. 
En el entorno actual de consumidores cada vez más sofisticados, aquellos que ofrecen experiencias memorables a los clientes crean valor superior y ventaja competitiva. Las experiencias son ahora parte de las ofrendas no solo de ocio y entretenimiento, sino también de negocios en general (Voss, 2004, p. 2).

El programa de Turismo Rural Comunitario en Perú involucra en su misión el desarrollo de valor en la experiencia, considerándolo como elemento diferenciador y agente de innovación. De este modo considera el valor de la experiencia como elemento que es determinado por la demanda, por la compatibilidad entre la expectativa del visitante y el producto ofrecido. Este valor hará que a medida que se vaya encontrando la expectativa del visitante y la realidad del producto, surja de manera espontánea aquello a lo que se denomina «vivencial», que está nutrido por la diversidad de elementos culturales y naturales auténticos, así como lo genuino de la experiencia del visitante (Mincetur, 2015, p. 7).

En este contexto el visitante adquiere una percepción del valor basado en beneficios percibidos en la experiencia representado por la diversidad de elementos culturales y naturales auténticos, así como otras actividades que complementan la experiencia en el destino. Es, en este aspecto que se infiere una gestión activa para el desarrollo de la entrega de valor en el aspecto estructural de la oferta y por otro lado se manifiesta un eje motivacional producido por la diversidad cultural y natural del destino.

En relación al producto, el turista participará activamente en la configuración del producto y en la experiencia turística, es el fenómeno de la cocreación y de los productos creativos, todo ello siguiendo la visión europea de la Economía de la Experiencia. En este contexto, los productos con más aceptación serán los ligados a la cultura, así como al cuidado del cuerpo y de la mente, todos ellos con altos valores. Una vez satisfecha la calidad racional (Q) los productos deberán buscar no defraudar en su calidad emocional (Qe) (Arroyo, 2011, p. 23).

Una consecuencia de la experiencia es el sentido de la cocreación de valor en donde el visitante o cliente participa en la entrega de valor, de la mano con la empresa.

El hecho de ubicar al ser humano en el eje central, en el campo del turismo, tiene otra ventaja. Nos incita a dejar de pensar solo en el turista que viaja o que está en un destino turístico concreto y nos obliga a pensar en el ser humano que se encuentra también en dicho destino y que es clave en esta red de turismo (Binkhorst, 2008, p. 48).

$\mathrm{Al}$ respecto Binkhorst (2008) reconoce que tanto el entorno que albergará la iniciativa como el visitante son valiosos en el diseño creativo de la entrega de valor. El visitante desarrolla un papel protagónico donde es cocreador y participante a la vez, una consecuencia de lo que llamamos «sociedad del conocimiento» motivados por el dinámico flujo de la comunicación, los visitantes desarrollan un rol movilizador de la información desarrollando una tendencia a participar y «ser parte de», un concepto que lo motiva a involucrarse con su vida cotidiana y convertirse en prosumers, ad prosumer o simplemente en generadores de contenidos. 


\section{Diseño de experiencias turísticas, como vehículo que conduce la experiencia}

\section{El hombre como actor principal de la experiencia turística}

El actor principal en la experiencia turística es el hombre y el desarrollo de este concepto se centra en él. Hay que mirar al turista como persona no como usuario de un servicio. El cliente no solo compra y consume, detrás de él hay toda una vida (Arroyo, 2011; Binkhorst, 2008). A partir de esta mirada, es más claro entender sus intereses y comprender sus necesidades, es también importante el contexto actual y la realidad en la que el hombre interactúa para comprender su actuación en la experiencia turística.

El nuevo turista, al que se conoce como Turista 2.0 o smart tourist, se mueve dentro de un entorno denominado SoLoMo (Social, Local y Móvil), en el que hay una gran interacción con otros usuarios que aconsejan sobre lugares o experiencias geolocalizadas, siendo el móvil una herramienta elemental para poder acceder a dicha información y generar otra nueva (Noguera, Gómez, \& Rabasa, s/f, p. 7).

Una característica de este nuevo turista y su relación con la tecnología y socialización en el entorno SoLoMo es la capacidad de convertirse en consumidor y productor de información y experiencias en la red, de esta realidad tangible se derivan los siguientes conceptos, según lo que señala Arroyo:

- Adprosumer: Productor y consumidor de información sobre bienes, productos y servicios, que a la vez anuncia en la web su satisfacción y experiencia (positiva o negativa), para conocimiento público.

- Proksumer: Es una persona netamente productora de información, basada en su propia experiencia, que a la vez sirve de intermediario de ese conocimiento para otras personas

- Prosumer: Productor y consumidor de información sobre bienes, productos y servicios, quién determina su usabilidad. (2011, pp. 25-26)

\section{Diseño de experiencias}

\section{Creando experiencias de valor y dimensiones de experiencias memorables}

En el escenario del mercado turístico la demanda se encuentra en la búsqueda de destinos que conecten al turista con «la esencia de un lugar y su gente». El turista busca ir mas allá de las rutas turísticas tradicionales, busca profundizar en experiencias locales auténticas, conectándose con personas de otras culturas de manera que enriquecen sus vidas y crean recuerdos duradero (Tourism and Events Queensland, 2015, p. 3).

Hay empresas que se dedican a conocer no solo el perfil de su consumidor sino, con mayor profundidad, a investigar cada una de las características «únicas» que lo hacen elegir este o aquel producto o servicio (Arroyo, 2011, p. 22). 
El desarrollo de productos turísticos debe considerarse una manera de facilitar «conjuntos de experiencias» para los turistas y basarse en la creación de combinaciones lógicas y accesibles, ya sea por temas o por zonas geográficas (Organización Mundial del Turismo - OMT y Comisión Europea de Turismo - CET, 2013, p. XI).

Es evidente la necesidad de trabajar en el desarrollo de productos turísticos con la capacidad de entregar experiencia como valor al visitante, pero desarrollarlo implica una estrategia de diseño acompañada de un plan de gestión que permita otorgar los resultados deseados.

\section{El diseño como vehículo de la experiencia turística}

El diseño cumple un rol en la experiencia turística y es el de encaminar la experiencia del visitante, despertando sus sentidos y manteniendo una «tensión dinámica» en el encuentro con la experiencia. El diseño en este sentido, guarda cada detalle de la entrega de valor al visitante, el mismo que debe tener una forma de control sobre ella y capacidad de medirse. Las empresas que no brindan experiencias consistentemente atractivas, sobrevaloran sus experiencias en relación con el valor percibido o sobreconstruyen su capacidad para realizarlas, obviamente verán presión sobre la demanda, los precios o ambos (Pine \& Gilmore, 1998, p. 105).

Pine y Gilmore (1998) aseguran que el planteamiento de diseños de experiencia no basta para el éxito, requiere de otros agentes y elementos a considerar como la oferta y demanda, pero sobre todo la gestión para asegurar la entrega de valor al visitante.

\section{La gestión, como impulsor de los modelos experienciales}

\section{Management o gestión}

Los autores coinciden en que existen numerosas definiciones sobre el concepto de management o gestión, de acuerdo con Mc Farland: «La gestión se define con fines conceptuales, teóricos y analíticos como el proceso mediante el cual los gerentes crean, dirigen, mantienen y operan la organización intencional mediante el esfuerzo humano cooperativo sistemático y coordinado» (citado en Mishra, 2008, p. 202).

Los procesos evidencian la necesidad de la cooperación humana de manera sistemática y coordinada, por ello, en esta forma inteligente, Henry Fayol ya había señalado que: «Administrar es predecir y planificar, organizar, compaginar, coordinar y controlar» (citado en Sarvaiya, 2013, p. 6).

Terry, define la gestión como un proceso «que consiste en la planificación, organización, actuación y control, realizadas para determinar y lograr los objetivos mediante el uso de personas y otros recursos» (citado en Prasad \& Gulshan, 2011, p. 7).

En una forma más elaborada y organizada sistémicamente, encontramos cuatro actividades presentadas por R. Terry: planificación, organización, actuación y control. 
En el concepto de R. Terry encontramos que planificar implica que los administradores desarrollan un constructo mental sobre las acciones a tomar para el logro de objetivos en un proceso ordenado y lógico. La organización significa que los gerentes o líderes coordinan los recursos humanos y materiales requeridos para el desarrollo de los objetivos. Actuar se convierte en el rol de los gerentes o líderes que motivan y dirigen a todos los involucrados en la labor requerida. Finalmente, el control consiste en asegurar que se siga con el plan establecido, corrigiendo cualquier desviación o inconveniente en la ejecución, tomando las decisiones correctivas necesarias.

La gestión, en ese sentido sirve como herramienta integradora de la planificación, organización, acción y control, aplicable a muchas actividades complejas como en el caso del turismo con características transversales y componentes sensibles como la población, el territorio, el patrimonio cultural y natural, la economía, etc. En el marco del desarrollo de operaciones que requieren objetivos concretos y medibles, esta nueva disciplina involucra, bajo este enfoque, a diversas actuaciones del hombre, en el caso del turismo, la gestión turística encuentra una amplia gama de actuaciones.

\section{La gestión como movilizador}

\section{Nada se mueve sin la gestión y el rol de la actitud como autogestión}

Controlar los diversos procesos en las operaciones turísticas resulta un tanto complicado, pero si a estas operaciones se les añade el complemento experiencial, el control debe ajustarse a la entrega de valor en el escenario turístico, tarea que se torna complicada pero que la gestión lo hace posible movilizando los recursos necesarios.

En el espacio turístico, el visitante maneja lo que Pine y Gilmore (1998) nombran como «las cuatro verdades de la experiencia». En él, se distinguen dos ejes, el primero sobre una participación de nivel pasivo a otro activo, y el segundo, de forma perpendicular que va de un estado inmerso de la experiencia a otro de absorción, espacio donde se mueve la experiencia.

De este modo, los estados de la experiencia se inician con una actitud frente a la realidad, esta actitud deviene de un estado personal, en el que podríamos ubicar el nivel de percepción en el modelo de «las cuatro verdades de la experiencia». Dentro del cual se explica las formas de interactuar con la experiencia, encontramos un elemento cuya presencia es tácita, esta es la actitud que actúa como iniciador de la experiencia y permanece en diferentes niveles o escalas de percepción.

Lo que importa en este sentido, es el manejo del proceso inicial de la experiencia, un agente dinámico en la experiencia llamado actitud como detonante y como elemento capaz de movilizar la atención durante la experiencia. Su relación involucra estados personales, aprendizajes y otros factores que determinan como enfrentar la realidad, los mismos que no pueden dejarse al azahar como en la naturaleza. En la delicada tarea de desarrollar experiencias turísticas, se debe seguir una adecuada planificación, organización, acción y control, para ello sirve la articulación de procesos que nos otorga la gestión o management. 
Figura 2. Los cuatro reinos de la experiencia.

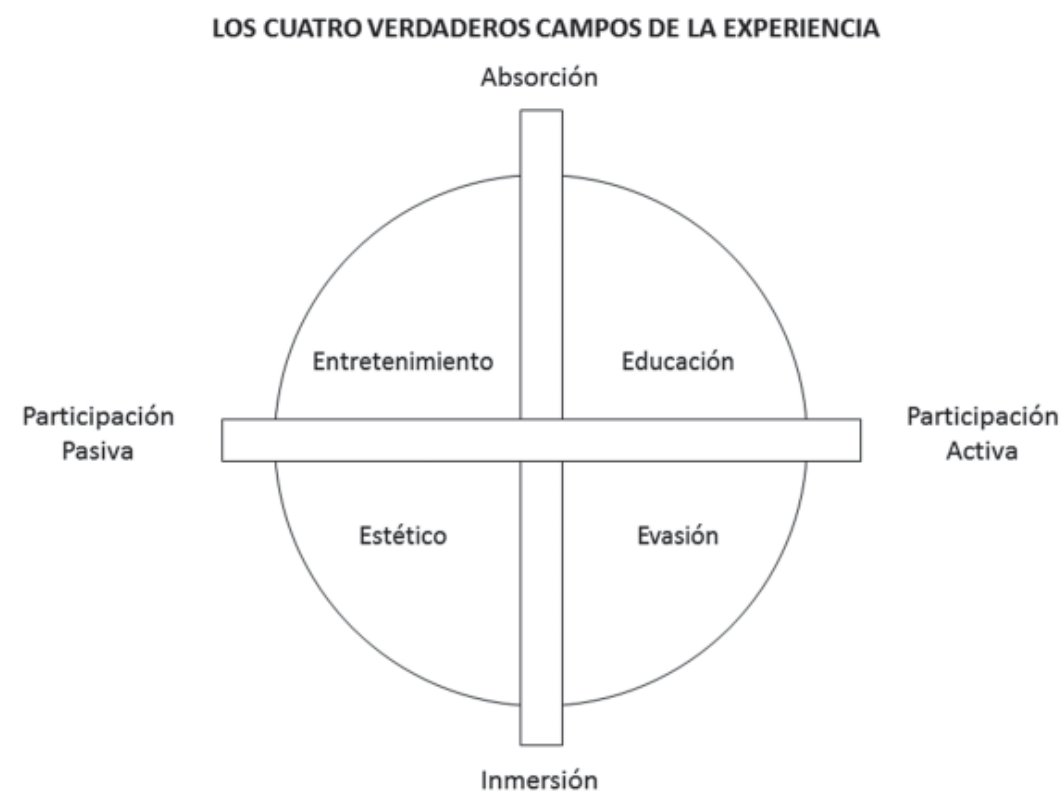

Fuente y elaboración: Traducido de Pine \& Gilmore, 1998, p. 98

Bajo esta mirada, el nivel de participación en la experiencia dependerá de la actitud del visitante (independientemente del estado de absorción o inmersión) ya sea durante toda la experiencia o en determinados momentos, la actitud juega un papel dinámico que provoca la participación. En el caso de la experiencia turística, la gestión es un elemento indispensable, es así como el grado de actitud promueve la participación en el visitante.

En un supuesto de no encontrar ninguna gestión o muy poca, respecto a una experiencia de viaje, el nivel de esfuerzo por que se logre, dependerá del grado de participación del visitante, implicándose en una autogestión de su propia experiencia.

Cuando la oferta, se encarga de los aspectos de gestión encontramos que la intervención del visitante es relativamente nula durante el desarrollo de la experiencia, la entrega de valor en la experiencia turística dependerá únicamente del esfuerzo del operador.

Es común encontrar blogs de aventureros viajeros, en donde explican a sus lectores sus vivencias pero sobre todo, la forma de como gestionaron sus propias experiencias, siguiendo en esta dinámica el rumbo de la autogestión para lograr su experiencia turística. No todos somos exploradores expertos y de alguna, mediana o mínima forma, gestionamos nuestras experiencias entregando la responsabilidad de la gestión a uno o varios operadores para que resuelvan nuestros problemas. 
En estos dos supuestos teóricos, encontramos la necesidad de ubicar puntos medios en su adaptación a la realidad. En la gestión de la experiencia turística, quien toma el rol de administrarla no siempre es el operador, esta responsabilidad pasa por varios ejecutores y también por el mismo visitante, considerando de esta manera distintos niveles de gestión e involucramiento.

\section{El guía, un facilitador que articula el vehículo con la experiencia como conductor en el camino de la realidad}

Otro aspecto de la gestión en la experiencia turística es la presencia de los guías turísticos como agentes de la experiencia, en ese sentido el rol que desempeñan tiene una finalidad adicional, y es la de servir de conductor de la experiencia en el modelo diseñado como vehículo para que el turista se envuelva en la experiencia turística.

Conducir a la experiencia, implica asumir un rol de facilitador o intérprete que de una manera muy personal muestra al visitante como manejarse en una situación experiencial, es quien facilita la comprensión de elementos diseñados en calidad de intérprete.

El circuito turístico se desarrolla con un guía en forma tradicional, pero ello no garantiza una experiencia memorable, lo usual es que alguien lo conduzca en el camino de la experiencia, no solo le describa lo que está frente a él, es importante la narrativa en la que el receptor encuentra significado, en mostrarle el uso y las formas. Esta forma de conducción es parte de la movilización de recursos humanos en la gestión.

¿Qué sucede cuando la actitud y la capacidad de nuestro visitante busca encontrar la experiencia turística a través de la autogestión? Es el caso especial de los aventureros, blogueros, viajeros, y algún tipo de trotamundos que busca siempre nuevas experiencias turísticas, ellos al emplear esta llamada autogestión movilizan también recursos humanos para interpretar o ayudarlos a manejar la experiencia pero no a través de un guía, sino a través del contacto con interlocutores válidos de la realidad que buscan desentrañar.

\section{Conclusiones}

La aplicación de la economía de la experiencia encuentra en el turismo una fuente importante de situaciones y casos, en el área empresarial no es muy difundida. En el caso de la gestión de destinos turísticos existe una tendencia promovida por la OMT en plantear experiencias turísticas memorables y transmitida a los países miembros, a manera de manuales y estudios centrados en su aplicación.

La experiencia como oferta económica es parte del contexto actual, se vislumbra una tendencia a futuro sobre las experiencias como transformación (Pine \& Gilmore, 2013). En el sector turismo es evidente la tendencia por las experiencias memorables y aunque existe poco material para su aplicación, en la práctica turística encontramos una fuente inagotable de experiencias que pueden ser ofrecidas a través de una adecuada gestión, en ese sentido revaloramos la necesidad de aplicar la gestión en función a las experiencias turísticas, para obtener verdaderos resultados; para ello, es necesario entender tendencias, preferencias, así como, la oferta y la demanda. 
El guía de turismo, asume un papel importante, es el facilitador de la experiencia turística, el profesional más involucrado con la gestión, con la conciencia ambiental y con la población anfitriona, pues como recurso humano y como parte del atractivo cultural trabaja como agente conductor de la cultura local en interacción con los visitantes, informando y mostrando los aspectos de la vida cotidiana local.

En cuanto a la actitud, es importante desarrollar más conocimiento sobre los elementos que influyen directamente en la actitud turística pues encuentro mucha potencialidad en su relación con la realidad y el espacio turístico, su presencia dinámica logra desarrollar niveles de atención antes, durante y después de la experiencia turística.

En cuanto a la gestión, es el control requerido para una adecuada entrega de valor y significado de la experiencia, sumado a la actitud tiene la capacidad de mover la experiencia entre los cuatro campos de la experiencia en el modelo propuesto por Pine y Gilmore (1998): The Four Realms of an Experience.

\section{Referencias}

Arroyo, R. (2011). La sociedad de ensueño del turismo. Turismo y Sociedad, 12, 17-26.

Arsenault, N., \& Gale, T. (2004). Defining Tomorrow's Tourism Product: Packaging Experiences Canadian Tourism Commission. ISBN: 0-662-38119-X. Recuperado de https://www.researchgate.net/publication/280385974_Defining_tomorrow's_tourism_ product_packaging_experiences

Barrios, M. (2012). Marketing de la Experiencia: principales conceptos y características. Palermo Business Review, 7(1), 67-83.

Ebejer, J. (2014). Meaning of place and the tourist experience. Institute for Tourism, Travel and Culture University of Malta. Recuperado de https://www.um.edu.mt/library/oar/handle/123456789/16638

Fernández-Balaguer, G. (2008). El plan de ventas. Augsburg: ESIC. ISBN: 8473565304, 9788473565301

Garrido, P. (2014). El turista conectado: de espectador a productor de contenidos. Recuperado de http://ddfv.ufv.es/xmlui/handle/ $10641 / 1024$

George, B. (2015). La búsqueda de la autenticidad. Antropología Experimental. Handbook of Tourist Behavior (15). Theory \& Practice editado por Metin Kozak, Alain Decrop. Recuperado de https://books.google.es/books?hl=es\&lr=\&id=LmORAgAAQBAJ\&oi =fnd\&pg=PA99\&ots=vXVad930Nc\&sig=Xvfl0D00HdKLj2qaKT0hkZYY_ug\#v=onepage\&q\&f=false

I.D.E.A. Agency (2012). Text100 Digital Index: Travel \& Tourism study. Recuperado de https://static.hosteltur.com/web/uploads/ 2012/12/Text100DigitalIndexTravelTourismStd.pdf

Kotler, P., \& Keller, K. L. (2012). Dirección de marketing. Pearson educación. ISBN: 978-607-32-1245-8

Kumar, N. (1998). A génesis of behavioural science. India: Gyan Publishig House. ISBN: 81-212-0566-2

La Liberté, M. (2005). La definición de una experiencia turística. Canadá: Tourism Intelligence Network. Recuperado de http:// tourismintelligence.ca/2005/03/23/defining-a-tourist-experience/

Mincetur (s/f). Programa Nacional de Turismo Rural Comunitario. Recuperado de http://legacy.iica.int/Esp/organizacion/LTGC/ agroturismo/Documentos\%20varios\%20\%20Andina/Programa\%20Nacional\%20de\%20Turismo\%20Comunitario\%20\%20Per\%C3\%BA.pdf

Mincetur (2015). Lineamientos para el desarrollo del turismo rural comunitario en el Perú. Recuperado de http://www.mincetur.gob.pe/ wp-content/uploads/2015/11/LINEAMIENTOS_DESARROLLO_TURISMO _RURAL_ARTE.pdf 
Mishra, R. (2008). Industrial Economics and Management Principles. Firewall Media. ISBN: 8131803015, 9788131803011

Morales, G. I., \& Hernández, J. M. (2011). Los stakeholders del turismo. Tourism \& Management Studies, 1.

Moscardo, G. (2009). Understanding tourist experience through mindfulness theory. Handbook of tourist behavior, 99-115.

Mckenzie, M. (2009). Experiential travellers and sustainable tourism. The Canadian Tourism Commission. Recuperado de https:// www.tourisme.gouv.qc.ca/activites/symposium-developpement-durable/presentations/19-0-08h20-1-Michele-McKenzieEN.pdf

Noguera, L., Gómez, J. M., \& Rabasa, A. (s/f). Replanteando modelos de negocio en turismo gracias al BIG DATA AECIT. Asociación Española de Expertos Científicos en Turismo. Recuperado de: http://www.aecit.org/files/congress/18/papers/35.pdf

Norther Ireland Tourist Board Creating (s/f). Experiences A Toolkit for the NI Tourism Industry nitb.com. Recuperado de https:// www.tourismni.com/globalassets/grow-your-business/toolkits-and-resources/experiences-guides/creating-experiences-toolkit.pdf

Nouvel, S. (31 de Mayo de 2017). Transformación Digital: no basta con buenas intenciones. Gestión. Recuperado de http://blogs. gestion.pe/la-economia-de-la-experiencia/2017/05/transformacion-digital-no-basta-con-buenas-intenciones.html

Organización Mundial del Turismo - OMT, \& Comisión Europea de Turismo - CET (2013). Manual de desarrollo de productos turísticos. Madrid: OMT. ISBN: 978-92-844-1415-4

Pine, B. J. (16 de enero de 2009). Joseph Pine en lo que los consumidores quieren [Archivo de video]. Recuperado de https://www. youtube.com/watch?v=2RD0OZCyJCk 3.50"

Pine, B. J., \& Gilmore, J. H. (1998). Welcome to the experience economy. Harvard business review, 76, 97-105.

Pine, B. J., \& Gilmore, J. H. (2013). The experience economy: past, present and future. Handbook on the experience economy, 21-44.

Prasad, L., \& Gulshan, S. (2011). Management Principles and Practices. India: Excel Books. ISBN: 9350620995,9789350620991

Rainforest Alliance (2010). Manual de buenas prácticas para turismo sostenible. Recuperado de http://www.rainforest-alliance.org/ business/tourism/documents/tourism_practices_guide_spanish.pdf

Reyes, B., \& Barrado, D. (2005). Nuevas tendencias en el desarrollo de destinos turísticos: Marcos conceptuales y operativos para su planificación y gestión. Cuadernos de turismo, 15, 27-44.

Sarvaiya, M. (2013). Management Concepts. Amazon International. ISBN: 9781304722478

Stange, J., Brown, D., Hilbruner, R., \& Hawkins, D. E. (2011). Tourism Destination Management. Achieving Sustainable and Competitive Results. Washington: US Agency for International Development.

Scott, N., Laws, E., \& Boksberger, P. (2013). Marketing of tourism experiences. Londres: Routledge.

Tourism and Events Queensland (2015). Hero Experiences Guidebook Creating memorable visitor experiences. Recuperado de https://cdn-teq.queensland.com/ /media/d8ab2695794b4627a67ab7aa1ebc9863.ashx?la=en-au\&vs=1\&d=20150717T155549

Voss, C. (2004). Trends in the experience and service economy: The experience profit cycle. London Business School. Recuperado de https://www.researchgate.net/profile/Chris_Voss/publication/242274223_Trends_in_the_Experience_and_Service_ Economy_The_Experience_Profit_Cycle/links/02e7e532026dedb147000000.pdf

Wang, N. (1999). Rethinking authenticity in tourism experience. Annals of tourism research, 26(2), 349-370.

Wong, M., Cheung, R., \& Wan, C. (2013). A study on traveler expectation, motivation and attitude. Contemporary Management Research, 9(2), 169.

World Economic Forum (2015). The Travel \& Tourism Competitiveness (Report 2015). ISBN-13: 978-92-95044-48-7. Recuperado de http://www3.weforum.org/docs/TT15/WEF_Global_Travel\&Tourism_Report_2015.pdf 